\title{
Engineering Tough Materials: Biomimetic Eggshell
}

\author{
Preliminary Research Report, January 30, 2015
}

Dr. Michelle L. Oyen (with PhD student H. Burak Caliskan)

Cambridge University Engineering Dept.

Trumpington Street

Cambridge, CB2 1PZ

UK

Approved for public release;distribution unlimited

\begin{abstract}
This preliminary report has two parts. First, the literature on biomimetic calcite synthesis is reviewed, with an aim of establishing gold-standard techniques for making biomimetic eggshell in large quantities. The literature is found to be surprisingly uniform in that most controlled studies of calcite biomineralization have utilized a vapor diffusion technique, where calcium is in solution and carbon and oxygen atoms or ions are introduced as a gaseous phase. Although well controlled, this process is slow and produces small quantities of material. As such, the evidence supports our continuing with solution-based calcite synthesis with a mind towards scale-up of material synthesis for eggshell-like material in large quantities. Second, the results of a series of preliminary experiments on this project are presented, comparing calcitic materials we produce with natural eggshell. Spectroscopy is utilized for examining the mineralization of calcite and the presence of amorphous calcium carbonate in the calcite matrix. Thermal analysis is used to establish the presence of organic materials within calcium carbonate. Next steps on this project will add a focus on how little is known about the quantitative thermodynamics of calcite formation in the presence of organic molecules, such as eggshell proteins, in order to facilitate larger-scale production of eggshell-like organic-inorganic composite materials.
\end{abstract}




\section{Report Documentation Page}

Public reporting burden for the collection of information is estimated to average 1 hour per response, including the time for reviewing instructions, searching existing data sources, gathering and maintaining the data needed, and completing and reviewing the collection of information. Send comments regarding this burden estimate or any other aspect of this collection of information, including suggestions for reducing this burden, to Washington Headquarters Services, Directorate for Information Operations and Reports, 1215 Jefferson Davis Highway, Suite 1204, Arlington VA 22202-4302. Respondents should be aware that notwithstanding any other provision of law, no person shall be subject to a penalty for failing to comply with a collection of information if it does not display a currently valid OMB control number.

\begin{tabular}{|c|c|c|}
\hline $\begin{array}{l}\text { 1. REPORT DATE } \\
\mathbf{3 0} \text { JAN } \mathbf{2 0 1 5}\end{array}$ & 2. REPORT TYPE & $\begin{array}{l}\text { 3. DATES COVERED } \\
\mathbf{0 0 - 0 0 - 2 0 1 5} \text { to 00-00-2015 }\end{array}$ \\
\hline \multirow{3}{*}{\multicolumn{2}{|c|}{$\begin{array}{l}\text { 4. TITLE AND SUBTITLE } \\
\text { Engineering Tough Materials: Biomimetic Eggshell }\end{array}$}} & $\begin{array}{l}\text { 5a. CONTRACT NUMBER } \\
\text { W911NF-14-1-0624 }\end{array}$ \\
\hline & & 5b. GRANT NUMBER \\
\hline & & 5c. PROGRAM ELEMENT NUMBER \\
\hline \multirow{3}{*}{\multicolumn{2}{|c|}{ 6. AUTHOR(S) }} & 5d. PROJECT NUMBER \\
\hline & & 5e. TASK NUMBER \\
\hline & & 5f. WORK UNIT NUMBER \\
\hline \multicolumn{2}{|c|}{$\begin{array}{l}\text { 7. PERFORMING ORGANIZATION NAME(S) AND ADDRESS(ES) } \\
\text { Cambridge University ,Engineering Department,Trumpington } \\
\text { Street,Cambridge, CB2 1PZ, UK, }\end{array}$} & $\begin{array}{l}\text { 8. PERFORMING ORGANIZATION REPORT } \\
\text { NUMBER } \\
\text {; 1739-EN-01 }\end{array}$ \\
\hline \multirow{2}{*}{\multicolumn{2}{|c|}{$\begin{array}{l}\text { 9. SPONSORING/MONITORING AGENCY NAME(S) AND ADDRESS(ES) } \\
\text { Army Engineer Research \& Development Center - International } \\
\text { Research Office, ERDC-IRO, ATT: RICHMOND, Unit 4507, APO, AE, } \\
\text { 09421 }\end{array}$}} & 10. SPONSOR/MONITOR'S ACRONYM(S) \\
\hline & & $\begin{array}{l}\text { 11. SPONSOR/MONITOR'S REPORT } \\
\text { NUMBER(S) } \\
\text { 1739-EN-01 }\end{array}$ \\
\hline
\end{tabular}

12. DISTRIBUTION/AVAILABILITY STATEMENT

Approved for public release; distribution unlimited

13. SUPPLEMENTARY NOTES

14. ABSTRACT

This preliminary report has two parts. First the literature on biomimetic calcite synthesis is reviewed with an aim of establishing gold-?????standard techniques for making biomimetic eggshell in large quantities. The literature is found to be surprisingly uniform in that most controlled studies of calcite biomineralization have utilized a vapor diffusion technique where calcium is in solution and carbon and oxygen atoms or ions are introduced as a gaseous phase. Although well controlled this process is slow and produces small quantities of material. As such the evidence supports our continuing with solution-?????based calcite synthesis with a mind towards scale-?????up of material synthesis for eggshell-?????like material in large quantities. Second the results of a series of preliminary experiments on this project are presented comparing calcitic materials we produce with natural eggshell. Spectroscopy is utilized for examining the mineralization of calcite and the presence of amorphous calcium carbonate in the calcite matrix. Thermal analysis is used to establish the presence of organic materials within calcium carbonate. Next steps on this project will add a focus on how little is known about the quantitative thermodynamics of calcite formation in the presence of organic molecules such as eggshell proteins in order to facilitate larger-?????scale production of eggshell-?????like organic-?????inorganic composite materials.

\section{SUBJECT TERMS}

16. SECURITY CLASSIFICATION OF:

a. REPORT unclassified b. ABSTRACT unclassified c. THIS PAGE unclassified
17. LIMITATION OF ABSTRACT

Same as Report (SAR)
18. NUMBER 19a. NAME OF OF PAGES $\quad$ RESPONSIBLE PERSON
10 


\section{Introduction}

The physical structure of the eggshell is the basis of its strength. An eggshell is made up of $\sim 95 \%$ calcium carbonate in the form of calcite, one of the most widespread mineral compounds in nature. Biomaterials are almost always the outcome of an organic-inorganic collaboration. Eggshells contain a few percent of organic material, largely protein, which contribute to the physical properties of the final material. Natural minerals are in fact formed through an organicinorganic interplay; biomineralization is itself regulated by protein (Figure 1). The mechanisms by which the organic content regulates biomineralization are poorly understood. There is very little information, for instance, on the thermodynamics of biomineralization [Navrotsky 2004]. Although, state-of-theart techniques for calcium carbonate synthesis in the presence of various organic and inorganic molecules provide an opportunity for studying the formation of biominerals at the molecular level, almost all of the information that the current literature offers is only qualitative. Unravelling these mechanisms quantitatively could pave the way to engineering bio-inspired materials, and is absolutely critical in scale-up of materials synthesis from small-scale laboratory experiments to military-scale materials applications.

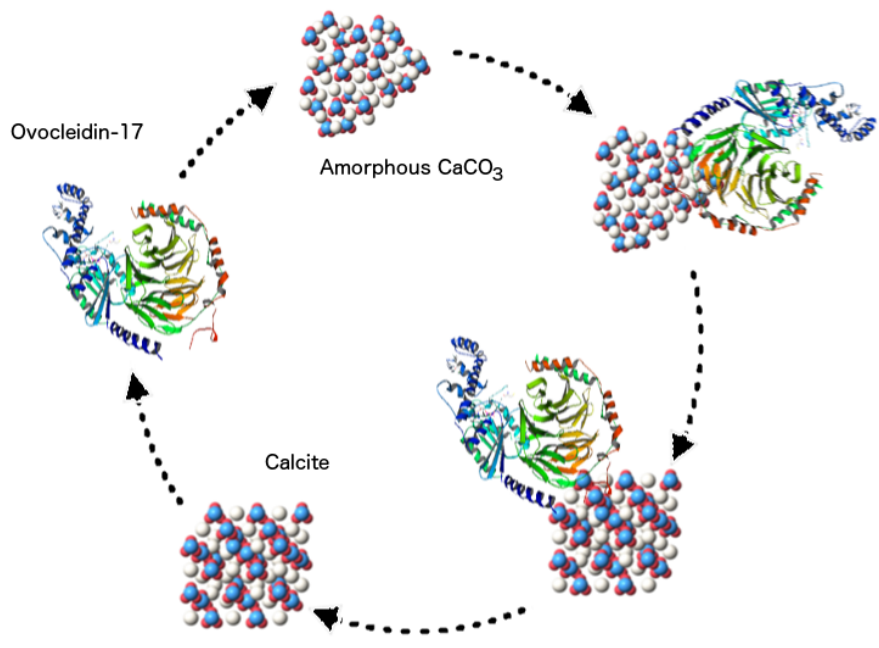

Figure 1. Schematic representation of the functional mechanism of ovocleiden17, a protein thought to be crucial in eggshell calcite biomineralization. (Protein structure was downloaded from Wikimedia Commons [http://commons.wikimedia.org/wiki/Category:Images])

\section{Calcite synthesis}

Calcium carbonate forms easily by precipitation out of solution, and is typically found in one of three crystalline polymorphs, calcite, vaterite and aragonite. It can be synthesized by simply mixing solutions of calcium chloride $\left(\mathrm{CaCl}_{2} \cdot 2 \mathrm{H}_{2} \mathrm{O}\right)$ and sodium carbonate $\left(\mathrm{Na}_{2} \mathrm{CO}_{3}\right)$ or sodium bicarbonate $\left(\mathrm{NaHCO}_{3}\right)$. Our laboratory typically uses both solutions at $200 \mathrm{mmol}$, mixing to combine directly or using syringe pumps to slowly infuse each solution into a vessel for mixing. We have also developed an alternate soaking (AS) technique for forming calcium carbonate in the presence of organic molecules, by mixing organics (in our 
particular case, the protein gelatin) in with these same stock solutions and then dipping a substrate in each of four beakers for a prescribed number of cycles (Figure 2). Other studies using solution-based calcite synthesis have included the use of natural calcite crystals with freshly cleaved surfaces to aid in crystal nucleation [Elhadj et al. 2006]. Our focus in the last few years has always involved solution-based formation of calcium carbonate (and calcium phosphate [Strange and Oyen 2011] in earlier work), but for the first Aim of this project, the literature was reviewed to establish the options for calcite synthesis and the potential for large-scale production of eggshell-like biomimetic material. (NB that this report's references are not inclusive of the literature surveyed.)

The vast majority of research into biomimetic mineralization [GomezMorales et al. 2010] has utilized a vapor diffusion process [Addadi et al. 1987] for calcium carbonate formation. In this process, calcium chloride is in solution, but the carbonate atoms are in gas form, often from ammonium carbonate powder, which vaporizes easily. The ammonium carbonate dissociates, and the carbon dioxide vapor interacts with the calcium in solution to precipitate calcium carbonate. A variation on this approach bubbles carbon dioxide gas directly into a calcium solution to achieve the same effect [Lakshminarayanan et al. 2006].

The vapor deposition process has been modified to incorporate a wide range of organic molecules [Meldrum 2003], both natural and synthetic, to examine how these organic molecules influence the types (polymorphs) of calcium carbonate present, the size and shape of crystals, and their orientation. The influence of inorganic substitutions, of magnesium for calcium in particular, has also been widely examined [Gower 2008]. The vapor deposition process has been used specifically in the study of biomimetic eggshell in at least two research groups [Fernandez et al. 2004; Lakshminarayanan et al. 2006]. Small modifications to the vapor diffusion method include the use of a polymerinduced liquid precursor (PILP) [Gower and Odom, 2000] or a modification to the precise structural set-up of the vapor diffusion chamber [Gomez-Morales et al. 2010] but these are all clearly small tweaks on the overall same process.

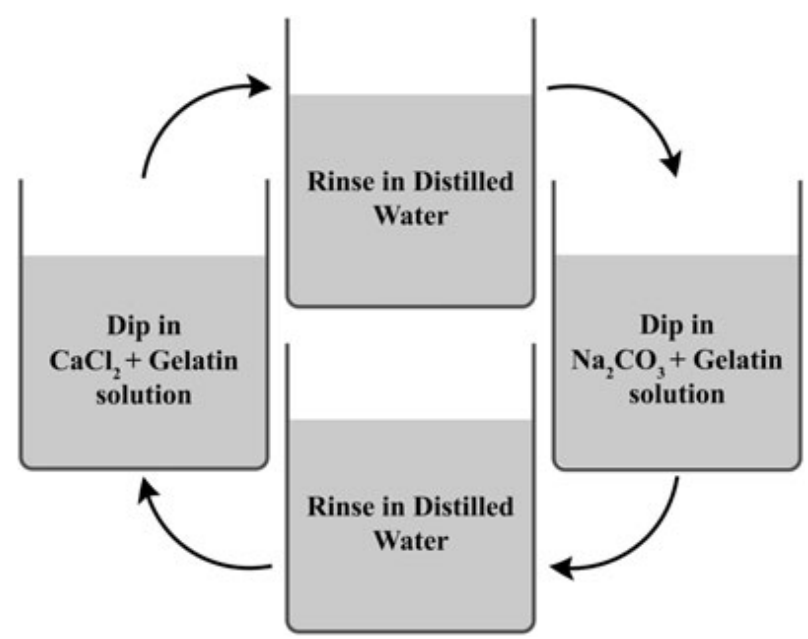

Figure 2. The four step alternate soaking process for forming calcium carbonate with gelatin [Armitage et al. 2012]. Both the $\mathrm{CaCl}_{2}$ and $\mathrm{Na}_{2} \mathrm{CO}_{3}$ solutions are 200 mmol, with between 2.5 and $15 \mathrm{~g}$ of powdered gelatin added to each $200 \mathrm{~mL}$ beaker of solution. 
The challenge with a vapor diffusion process from a scale-up perspective is that it is slow, taking as long as several days to form calcium carbonate [Addadi et al. 1987]. This makes it an acceptable vehicle for studying basic aspects of mineralization in an extremely controlled manner, such as the influence of the presence of various organic molecules, but for the manufacture of large scale materials it is impractical. The AS process is relatively faster, but the process is overall not very well controlled. The act of forming calcium carbonate by just mixing solutions is also not well controlled, and there is insufficient time for organic molecules to influence the process, and become incorporated into the crystals, making it not very biomimetic and unlikely to yield material with the desired robust mechanical properties, and fracture toughness in particular. In addition to challenges with reaction rate, in all of these cases a major limitation to the calcite formation is in the size of the crystals formed. While natural eggshell is up to millimeters thick with nearly throughthickness calcite crystals, the crystals reported in biomimetic biomineralization works are micrometers in size. After 100 cycles of the AS process, the crystals were approximately $4 \mu \mathrm{m}$ in diameter, compared with sub-1 $\mu \mathrm{m}$ after the first cycle [Armitage et al. 2012].

Limiting the literature on optimized large-scale biomimetic calcite synthesis with the incorporation of organic molecules is the lack of quantitative thermodynamic data about the process of eggshell biomineralization. Overall eggshell has been studied dramatically less than other calcium carbonate materials, such as nacre and various marine organisms. The production of a complete chicken eggshell takes only 18 hours. Research on eggshell has largely been confined to the food (poultry) industry, and interest in mechanical properties of egg was mostly concerning the transport of eggs to supermarkets. It is largely suspected that, as with many other biomineralization processes, there is a multi-step formation process with calcite as an end result (Figure 3) and intermediate phases of amorphous calcium carbonate, vaterite and aragonite [Gower 2008]. This hypothesis is consistent with the co-existence of all three crystalline phases in nature, since the vaterite and aragonite are metastable and calcite is the final stable product. An important role of this mechanism is to allow the organism to mold the amorphous form in any desired shape to produce complex architectures. This mechanism was shown to be possible in the context of reprecipitation of quail eggshell [Lakshminarayanan et al. 2006]. The role of proteins in the amorphous precursor phase is proposed to be crucial because of their ability to keep the amorphous form stable until the crystal transformation is needed [Gower 2008]. A thorough understanding of how this mechanism is used by living organisms is desirable to enable production of biomimetic inorganic materials in large quantities. 


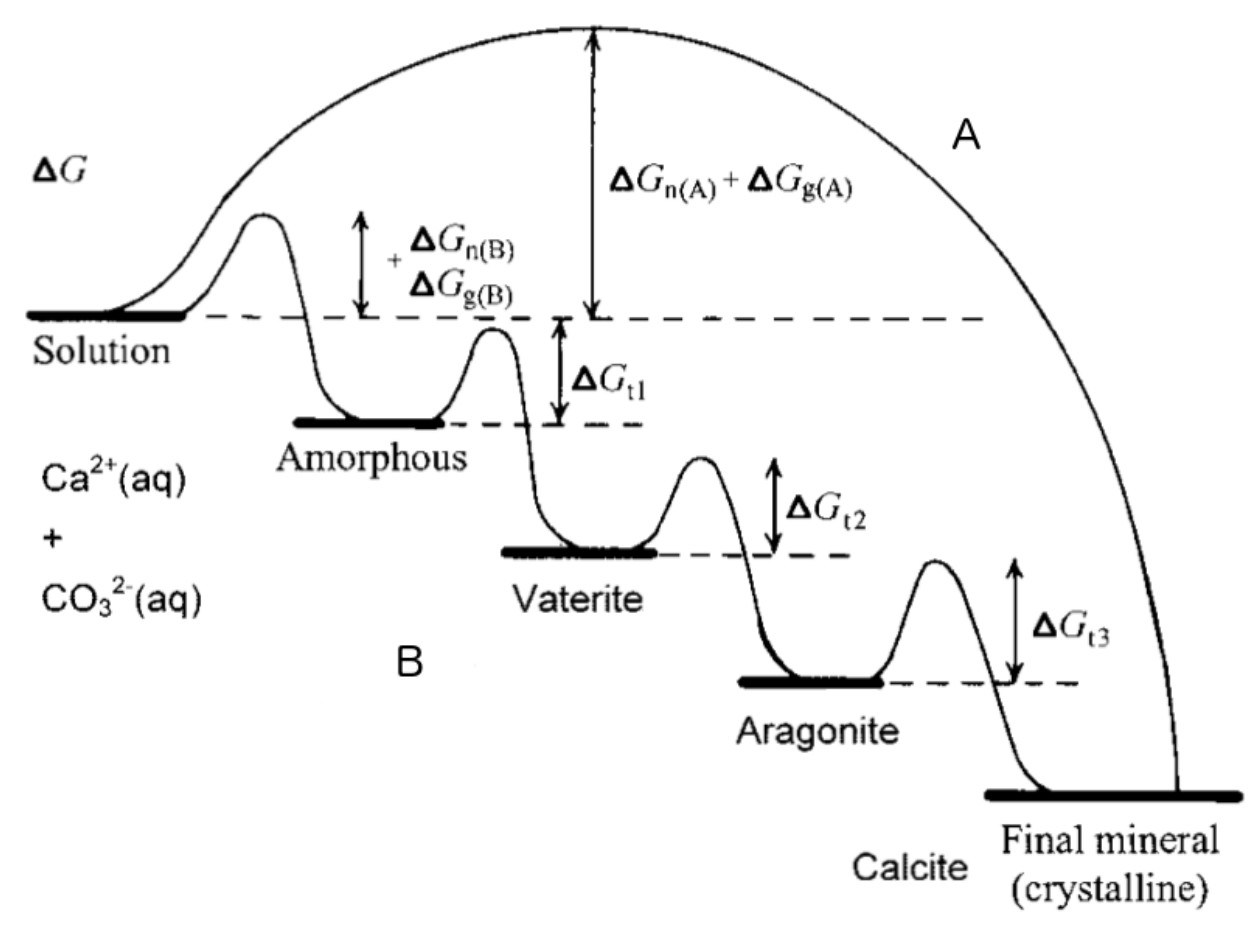

Figure 3. Reaction coordinate diagrams of classical nucleation single reaction (A) and likely biomineralization multiple-reaction (B) pathways. (Adapted from [Gower 2008].)

\section{Preliminary Experiments}

Biological mineral formation requires the precipitation of inorganic crystals from a solution. Although it is now widely accepted that the first phase in biomineralization is an unstable amorphous form, which then transform to meta-stable and finally to a stable crystal, precipitation from a solution is still the key step for almost all mineralization processes in nature. It is then reasonable to analyze mineralization not only after the solid inorganic material formation, but also during the crystallization of the mineral. Spectroscopy is one of the most convenient methods to study mineralization during crystal formation. This technique allows monitoring mineral formation in real-time, thereby providing a method to study the kinetics of trans- formation of the amorphous precursor phase.

We therefore use Fourier Transform InfraRed spectroscopy (FTIR) as a useful tool for examining calcite formation, via a Perkin-Elmer Spotlight 100 Attenuated Total Reflection Fourier Transform InfraRed (ATR-FTIR) spectrometer. Figure 4 shows the spectrum for commercially available (Sigma Aldrich) calcite powder as a reference. The spectra for three types of natural eggshell show a calcite-dominance with small residual "bumps" at the location indicating amorphous calcium carbonate (Figure 5). A time sequence of FTIR scans from immediately after $\mathrm{CaCl}$ and $\mathrm{NaHCO}_{3}$ (both Sigma Aldrich) solution mixing to 30 minutes later demonstrates the development of the calcite peaks and the diminution, but not complete removal, of the amorphous signal (Figure 6). 


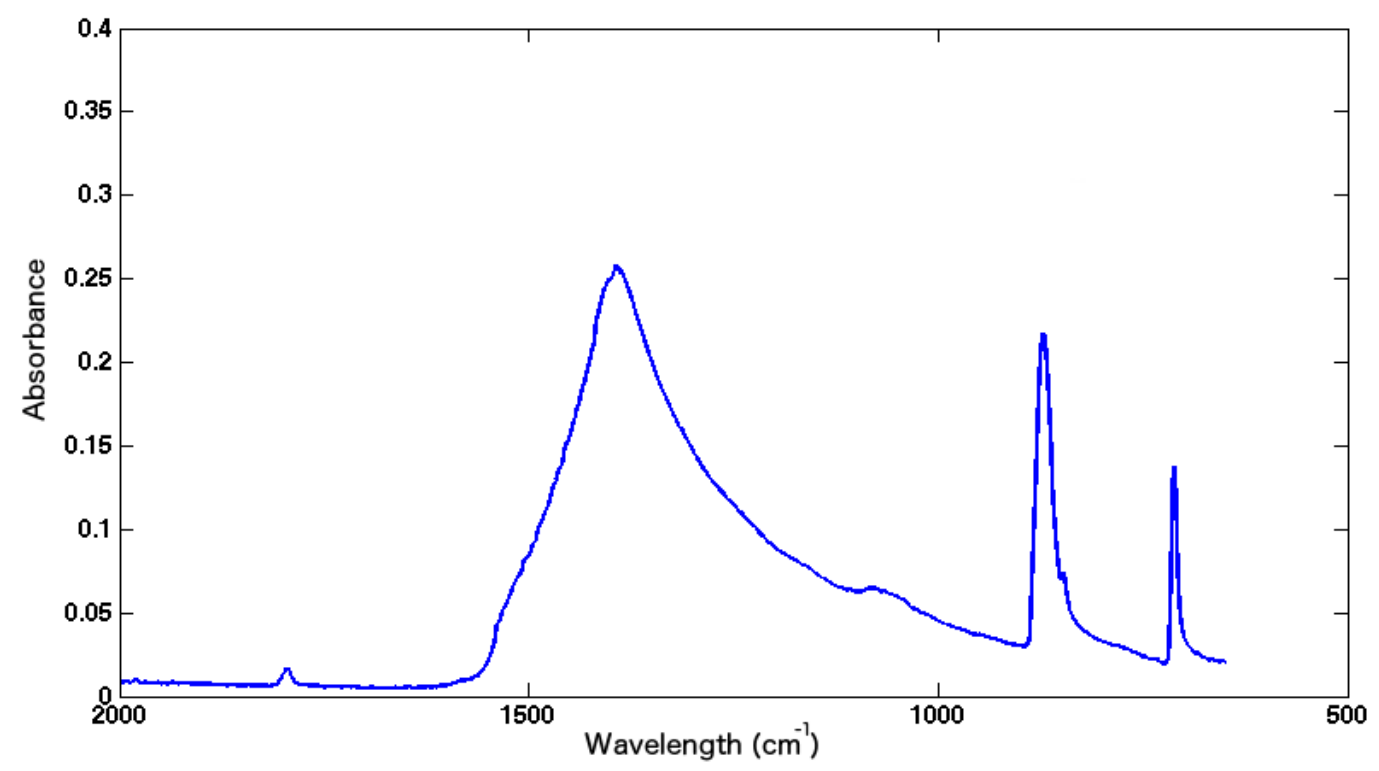

Figure 4. The FTIR spectrum of commercial $\mathrm{CaCO}_{3}$ calcite powder (Sigma Aldrich). Absorption peaks at $1414 \mathrm{~cm}^{-1}, 872 \mathrm{~cm}^{-1}$ and $712 \mathrm{~cm}^{-1}$ are specific to calcite.

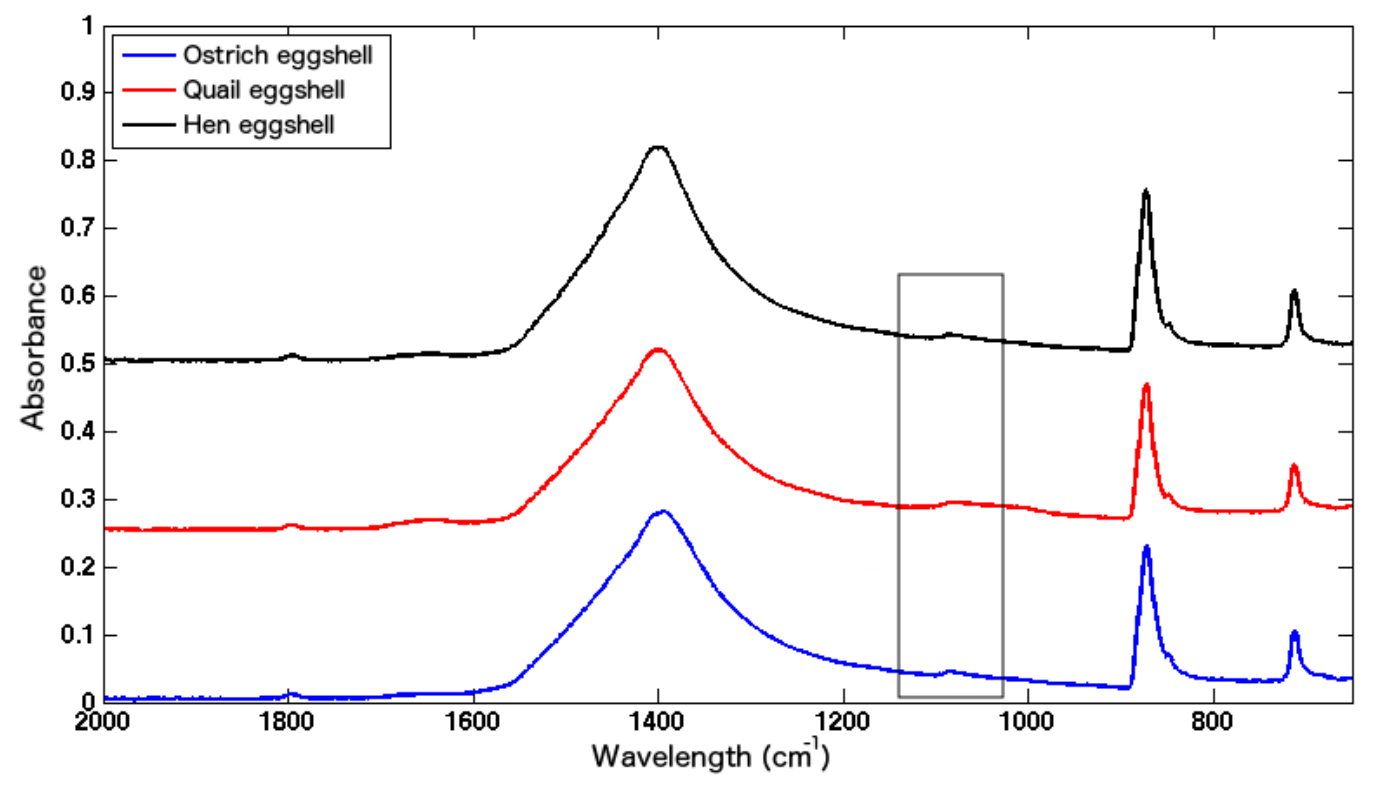

Figure 5. The FTIR spectra of ostrich, quail and hen eggshells. The rectangle shows amorphous calcium carbonate absorption peaks at $1086 \mathrm{~cm}^{-1}$. Small organic peaks can be observed at $1648 \mathrm{~cm}^{-1}$. 


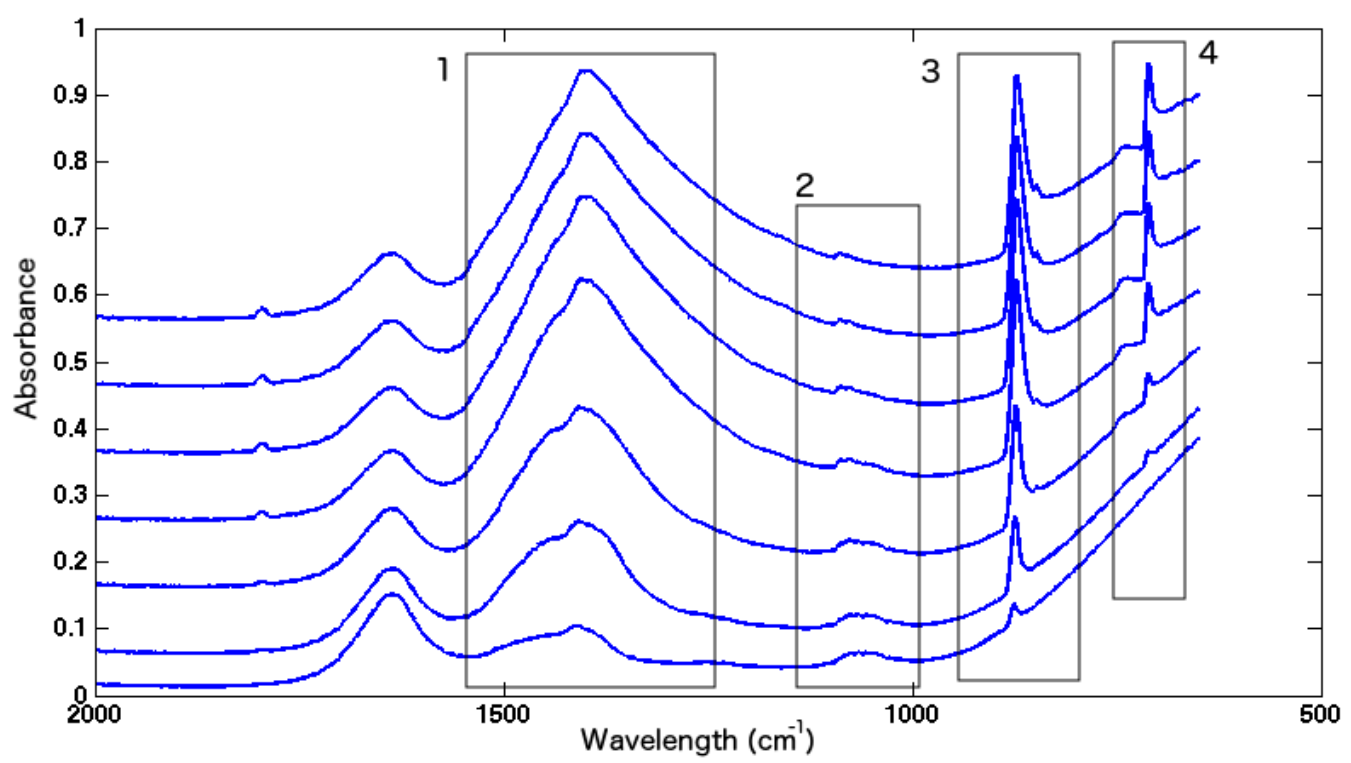

Figure 6. The spectra of $\mathrm{CaCO}_{3}$ mineralization for 30 min upon mixing $\mathrm{CaCl}$ and $\mathrm{NaHCO}_{3}$ solutions. Spectra show the amorphous to crystal transformation from the beginning (bottom) to the end of mineralization (top) in time sequence. Rectangles $2\left(1086 \mathrm{~cm}^{-1}\right)$ and 1-3-4 $\left(1414 \mathrm{~cm}^{-1}, 872 \mathrm{~cm}^{-1}\right.$ and $\left.712 \mathrm{~cm}^{-1}\right)$ indicate the amorphous and calcite specific peaks, respectively.

Because biological minerals contain organic molecules, the interplay of proteins with inorganic crystals is a key process, which requires protein purification and protein analysis, both of which are ongoing. Moreover, the occlusion of organic content into calcite crystals is a crucial part of this study and can be observed using thermogravimetric analysis (TGA, Perkin-Elmer) in order to understand the nature of protein preservation within calcite crystals. The weight loss of the crystals before calcite starts to melt gives the approximate percentage of organic matter in the crystal lattice. This is shown for natural chicken eggshell in Figure 7, showing a few percent weight loss at a mid-range temperature far lower than the dissociation temperature of calcite itself (around $800^{\circ} \mathrm{C}$ ). This is consistent with the couple of percent of organic material known to be present in natural eggshell. The same general result is observed (Figure 8) when we make calcite in solution in the presence of bovine serum albumin (BSA), a commercially available (Sigma Aldrich) model protein we are using as a stand-in for the eggshell proteins we are currently working to purify. Calcite made using the same solutions and process but no protein present does not have any appreciable weight loss across the same temperature range (Figure 9), supporting the idea that this weight loss is uniquely associated with the protein or other organic material included in the calcite in either natural shell synthesis (Figure 7) or biomimetic calcite formation (Figure 8). 


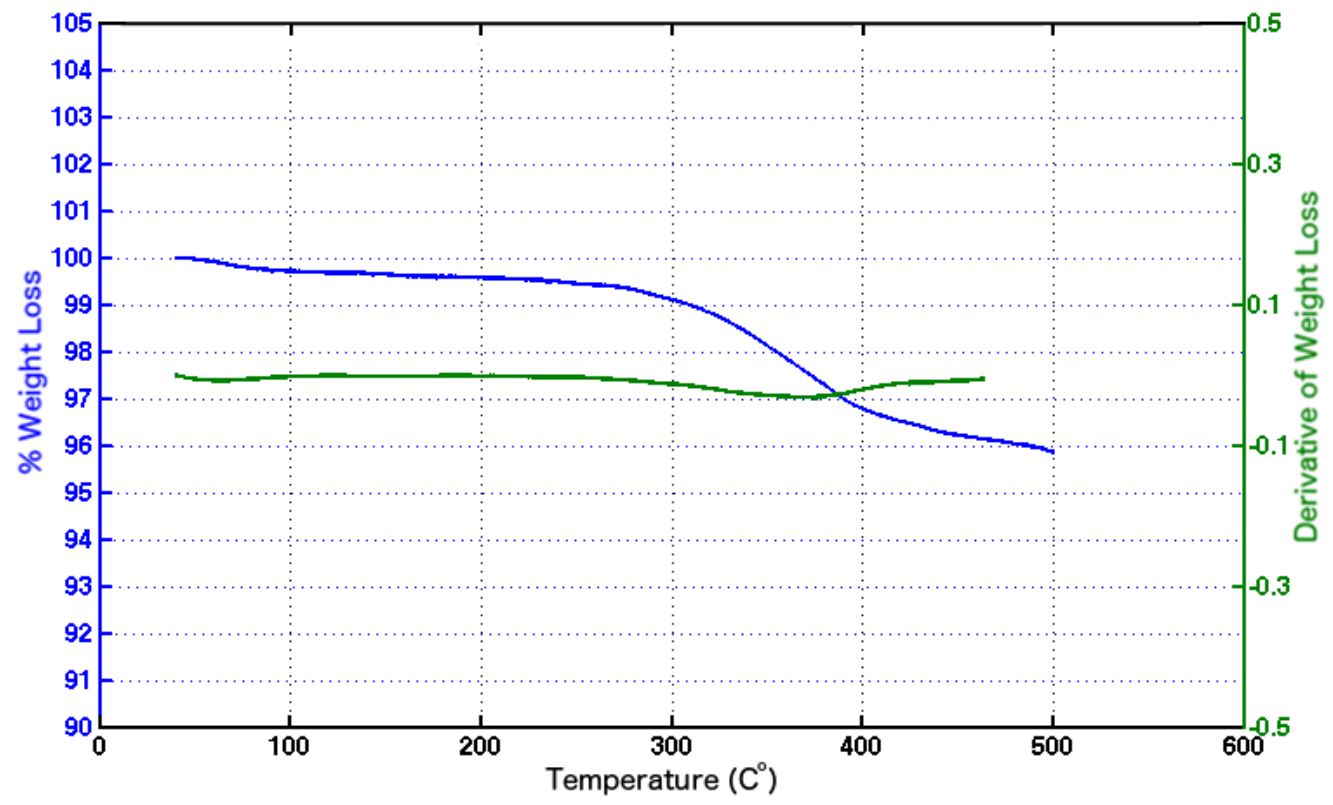

Figure 7. TGA result for chicken eggshell. The weight loss at $350^{\circ} \mathrm{C}$ can be attributed to intra-crystalline protein degradation.

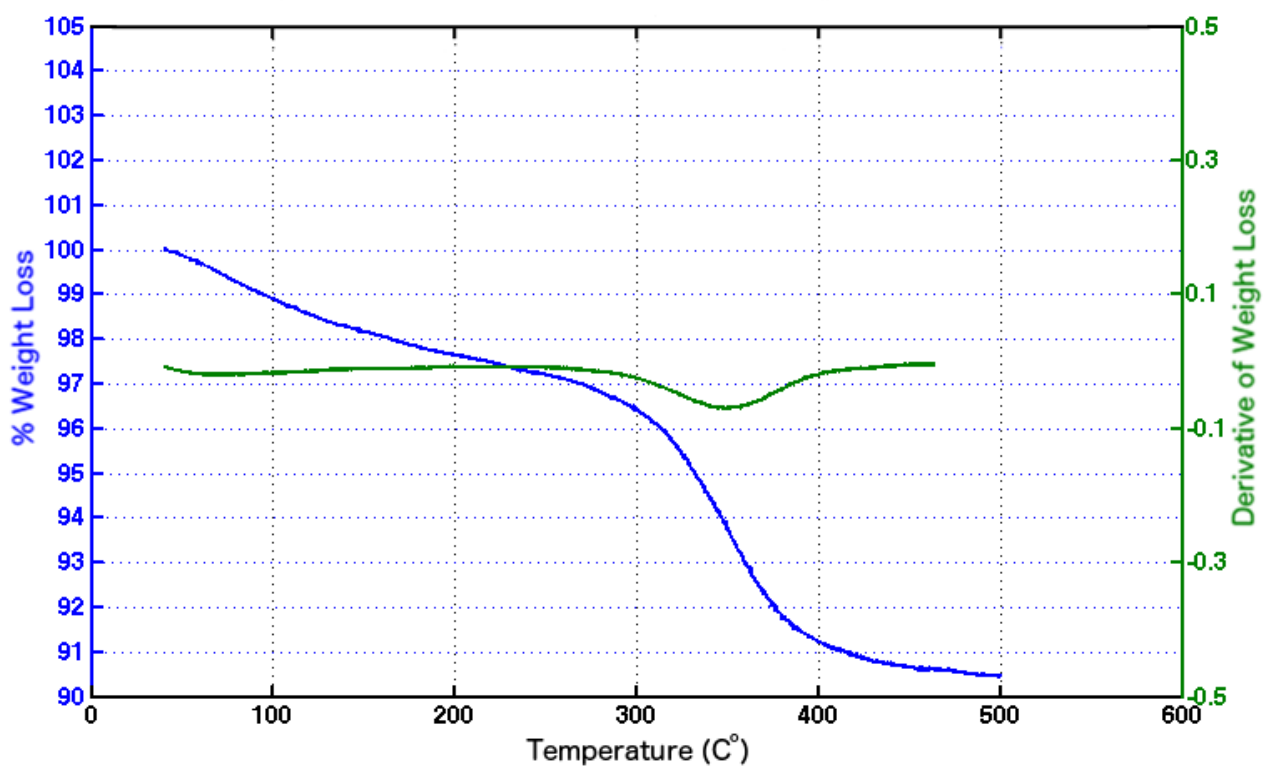

Figure 8. TGA result for calcite crystals grown in solution in the presence of bovine serum albumin protein (a well-characterized model protein available commercially, Sigma Aldrich). The overall picture is similar to that for natural eggshell with integrated protein (Figure 7). 


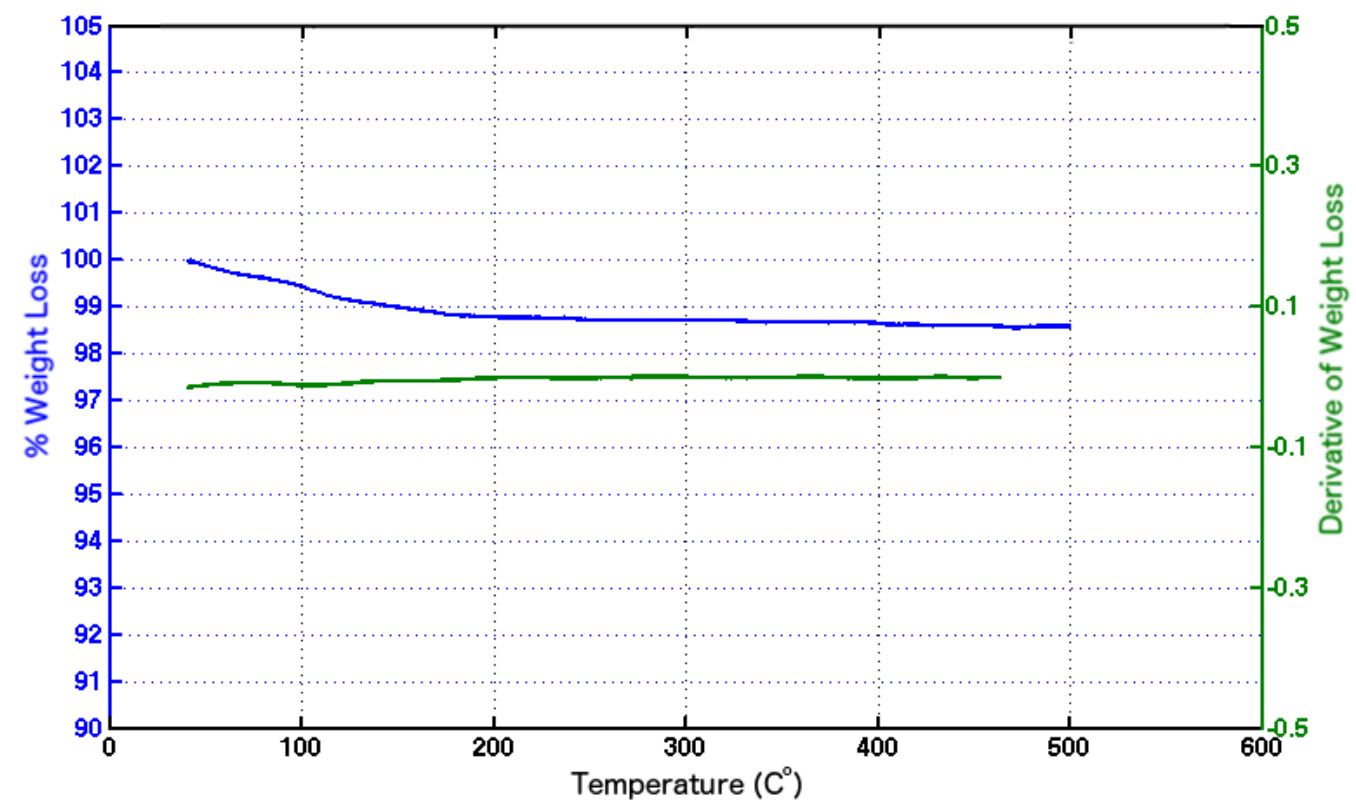

Figure 9. TGA result for calcite grown in solution in the absence of any added protein. In contrast to both natural eggshell (Figure 7) or lab-synthesized calcite with BSA protein included (Figure 8) there is approximately zero weight loss at temperatures less than $600^{\circ} \mathrm{C}$, above which dissociation of the calcite itself is expected.

\section{Conclusion and Outlook}

Despite attracting little attention, an important aspect of mineralization is its thermodynamic nature. As is the case for all such studies, the most reliable method for extracting thermodynamic information is to use calorimetry. This will be a critical component of the next phase of this project. The aim is to gain quantitative understanding of the mineralization pathway proposed in Figure 3, and to establish whether this pathway is universally true (i.e. does the material always "stop" at each metastable phase in the figure, or perhaps does some calcite "jump" from amorphous calcium carbonate directly to calcite?). We previously observed that in solution-based calcium carbonate synthesis, we tended to obtain vaterite when there was no organic material (protein) present and calcite when organic material was present [Armitage et al. 2012]. This result will be replicated with quantitative measurements using calorimetry. We will further continue with the $2^{\text {nd }}$ and $3^{\text {rd }}$ Aims as laid out in the original proposal, examining the influence of texture and organic molecules isolated from natural eggshell on the formation of calcite. 


\section{References}

Addadi L, Moradian J, Shay E, Maroudas NG, Weiner S, A chemical model for the cooperation of sulfates and carboxylates in calcite crystal nucleation: Relevance to biomineralization. Proc. Natl. Acad. Sci. USA 84 (1987) 2732-6.

Armitage OE, Strange DGT, Oyen ML, Biomimetic Calcium Carbonate-Gelatin Composites as a Model System for Eggshell Mineralization. Journal of Materials Research 27 (2012) $3157-64$.

Elhadj S, Salter EA, Wierzbicki A, De Yoreo JJ, Han N, and Dove PM: Peptide controls on calcite mineralization: Polyaspartate chain length affects growth kinetics and acts as a stereochemical switch on morphology. Cryst. Growth Des. 6 (2006) 197-201.

Fernandez MS, Passalacqua K, Arias JI, Arias JL, Partial biomimetic reconstitution of avian eggshell formation. J. Structural Biol. 148 (2004) 1-10.

Gomez-Morales J, Hernandez-Hernandez A, Sazaki G, Garcia-Ruiz JM, Nucleation and polymorphism of calcium carbonate by a vapour diffusion sitting drop crystallisation technique. Cryst. Growth Des. 10 (2010) 963-9.

Gower, L. B. Biomimetic Model Systems for Investigating the Amorphous Precursor Pathway and Its Role in Biomineralization. Chemical Reviews 108 (2008) 4551- 4627.

Gower LB, Odom DJ, Deposition of calcium carbonate films by a polymer-induced liquid-precursor (PILP) process. J. Crystal Growth 210 (2000) 719-34.

Lakshminarayanan R, Loh XJ, Gayathri S, Sindhu S, Banerjee Y, Kini RM, Valiyaveettil S. Formation of transient amorphous calcium carbonate precursor in quail eggshell mineralization: an in vitro study.

Biomacromolecules. 7 (2006) 3202-9.

Meldrum FC, Calcium carbonate in biomineralisation and biomimetic chemistry. Intl. Mater. Rev. 48 (2003) 187-224.

Navrotsky, A. Energetic clues to pathways to biomineralization: Precursors, clusters, and nanoparticles. Proc. Natl. Acad Sci. USA 101 (2004) 12096-12101.

Strange DGT and Oyen ML, Biomimetic Bone-Like Composites Fabricated Through an Automated Alternate Soaking Process, Acta Biomaterialia 7 (2011) $3586-94$. 